\title{
EL CONSTRUCTIVISMO ÉTICO EN JUSTICE AS FAIRNESS*
}

\section{JOHANN S. BENFELD E. ${ }^{* *}$}

RESUMEN: Este artículo pretende precisar la noción de constructivismo ético tal como aparece en la filosofía de John Rawls. Para tal efecto, esta investigación avanza en la determinación conceptual de la idea de constructivismo ético desde una perspectiva metodológica general, para luego vincular los elementos de la teoría general con la propuesta de la justicia como equidad. Hecho lo anterior, muestra someramente los desplazamientos que experimenta la propuesta rawlsiana desde el constructivismo kantiano al político. Termina este trabajo con una consideración crítica de la estrategia de Rawls.

PALABRAS CLAVES: Ética - metaética - constructivismo ético - justicia como equidad - John Rawls.

\section{ETHICAL CONSTRUCTIVISM IN JUSTICE AS FAIRNESS}

ABSTRACT: This article intends to specify the notion of ethical constructivism as it appears in John Rawls' philosophy. To achieve this intent, this research progresses in the conceptual determination of the idea of ethical constructivism from a general methodological perspective, to later link the general theory elements to the proposal of justice as fairness. The article continues briefly describing the shift of Rawls' proposal from Kant's constructivism to a political one. It finishes with a critical consideration of Rawls' strategy.

KEY WORDS: Éthics - metaethics - justice as fairness - John Rawls.

\footnotetext{
* Fecha de Recepción: $1^{\circ}$ de junio de 2012.

Fecha de aceptación: 29 de noviembre de 2012.

** Profesor de Filosofía y Teoría del Derecho, Escuela de Derecho de la Pontificia Universidad Católica de Valparaíso. Correo electrónico: abogbenfeld@yahoo.com Quisiera agradecer especialmente al profesor doctor Miguel Ángel Rodilla, quien ha tenido la amabilidad de discutir este artículo conmigo. Si este trabajo tiene algún acierto, se lo debo a él; de todo lo obvio solo yo soy responsable.
} 


\section{1) CONSIDERACIONES PRELIMINARES}

En su artículo Kantian Contructivism in Moral Theory, de 1980, John Rawls declaraba: "En estas lecciones examino la noción de concepción moral constructivista, o, más exactamente, puesto que hay diferentes tipos de constructivismo, una variante kantiana de esta noción. La variante que voy a discutir es la de la justicia como equidad presentada en mi libro A Theory of Justice" ${ }^{1}$. Con semejante declaración, Rawls acometía la difícil empresa de justificar su propia teoría de la justicia desde una determinada perspectiva y no de la forma desarticulada en que hasta el momento lo había hecho. En efecto, en lo que a este tema se refiere "las consideraciones efectuadas por Rawls antes de 1980 adolecían de un excesivo eclecticismo y de una escasa sistematización interna: aparecían en ella elementos de las teorías de la decisión y los juegos, de la filosofía analítica, del contractualismo, del trascendentalismo kantiano, del intuicionismo moral; y todo ello, sin haberse logrado una coordinación integradora" ${ }^{2}$. Esto redundaba en cierta incertidumbre sobre la posición metaética de Rawls, debido a que en su teoría de la justicia apelaba "para fundamentar sus dos principios de justicia a prácticamente todos los recursos, excepto el teológico, que se han ensayado en la historia de la filosofía para fundamentar intersubjetivamente principios morales: el consentimiento, el autointerés, las intuiciones y los presupuestos formales del razonamiento moral"3.

Este intento de justificación teórica iniciado en la década de los 80 por el filósofo americano suponía un esfuerzo sistemático por comprender su propia teoría desde una perspectiva metaética constructivista, pero también la explicitación de un modelo de construcción y sus elementos. Dejaremos para más adelante el análisis del diseño mismo, concentrándonos por el momento en el enfoque metaético.

1 Rawls, John (1999) "Kantian Constructivism in Moral Theory", Collected Papers, Edited by S. Freeman. Massachusetts: Harvard University Press, p. 303. En adelante se citará esta obra como KC. Existe traducción castellana de la obra por M. A. Rodilla en Rawls, John (1986) Justicia Como Equidad. Madrid: Editorial Tecnos. Asimismo, para las referencias a $A$ Theory of Justice utilizaremos las siguientes ediciones: A Theory of Justice (original edition), Harvard University Press, 1971, que citaremos como "Theory original"; A Theory of Justice, Oxford University Press, 1985, que citaremos como "Theory"; y A Theory of Justice (Revised Edition), Harvard University Press, Massachusetts, 2000, que citaremos como "Theory rev." Massini Correas, Carlos (2004) Constructivismo Ético y Justicia Procedimental en John Rawls. México D.F.: Universidad Nacional Autónoma de México, pp. 21-22.

3 Nino, Carlos (1989) El Constructivismo Ético. Madrid: Centro de Estudios Constitucionales, p. 93. 


\section{2) ALGUNAS IDEAS GENERALES SOBRE EL CONSTRUCTIVISMO ÉTICO}

\section{1.) ÉTICA Y METAÉTICA}

En toda reflexión ética llevada hasta el final es dable encontrar, por una parte, un conjunto de principios y normas que prescriben cierta práctica, es decir, una ética sustantiva y, por otra, una consideración crítica sobre la justificación de tales principios y normas y sobre la naturaleza de sus enunciados, esto es, una metaética ${ }^{4}$. La idea de una "metaética" remi-

4 Hemos simplificado considerablemente la complejidad que entraña la propia división entre ética y metaética y la doble orientación que le atribuimos a esta última como fundamentación epistemológica y análisis del lenguaje. Intentemos, pues, clarificar estas ideas en unas pocas líneas. En el campo de la ética sustantiva es posible distinguir tres orientaciones: una "teleológica", una "deontológica" y otra "axiológica". La primera de ellas estima que la rectitud moral de una acción (objeto de la ética) reside en la realización del bien, que puede definirse en términos de placer, felicidad, utilidad, etc., de modo tal que si una determinada acción se encamina a la realización (o la maximización) del bien, ha de ser considerada moralmente correcta. La ética eudaimonista de Aristóteles es un buen ejemplo de este tipo de pensamiento. Por el contrario, una ética deontológica cifra la rectitud de la acción en el respeto de ciertas reglas y principios que establecen los términos debidos; así, por ejemplo, una acción es considerada "correcta" cuando es expresión de un imperativo de la razón que orientando a la voluntad del sujeto actuante lo hace realizar lo que es debido, incluso cuando ello no sea percibido como un bien inmediato por el individuo. Immanuel Kant es un buen representante de esta posición. Finalmente, una ética axiológica representa un término medio entre la ética teleológica y la deontológica al suponer que la orientación de la acción depende de la realización de un valor que, ya sea objetivo o subjetivo, determina un tercer ámbito de la realidad. Para las teorías axiológicas, en general, entre el mundo de las cosas naturales y el de las meras ideas está el de los valores que encuentra su sede natural en el campo de la cultura. De este modo la acción moralmente correcta tiende a un bien (teleológicamente); pero este no es una realidad natural sino un "valor" cuyo ámbito es la cultura humana, de modo tal que se trata de una autoprescripción de la acción que comporta cierta rectitud (deontología). Max Scheler es un buen representante de esta idea. Por su parte, la doble orientación de la metaética como fundamentación de principios y normas, y como análisis del lenguaje moral da como resultado que en ella podamos hablar de teorías metaéticas descriptivas y no descriptivas. Son descriptivas aquellas que preocupadas por la fundamentación epistemológica de los enunciados morales sostienen que existen hechos morales independientes de la ponderación de los mismos, y nuestras acciones y normas serán moralmente buenas en la medida en que se correspondan con ellos. En ese sentido los enunciados morales son susceptibles de ser discutidos desde el punto de vista de la verdad. El naturalismo y el intuicionismo son expresiones de estas ideas. Son teorías metaéticas no descriptivistas aquellas que sostienen que no existen hechos morales independientes de la ponderación de los individuos. Dentro de esta corriente, con todo, es posible distinguir dos grandes orientaciones: una emotivista (C.L. Stevenson y A.J. Ayer), y una prescriptivista (R.M. Hare). Para la primera, los enunciados morales expresan solo el estado anímico de aprobación o desaprobación de quien lo emite; así, decir "asesinar a una persona es malo", se debe traducir por "a mí me perturba emocionalmente que alguien muera a manos de otro". Esta posición hace imposible cualquier tipo de discurso ético. El prescriptivismo, por su parte, asigna a los enunciados morales un estatuto lógico diferente de las sentencias asertivas, al concebirlos como prescripciones universales. Ahora bien, conforme al esbozo precedente, una teoría ética constructivista es de naturaleza deontológica, y prescriptiva. Con ello, con todo, no queremos significar que toda teoría ética constructivista sea deontológica al modo kantiano y prescriptiva al modo de Hare; por lo pronto la propuesta por Rawls no es, en 
te, en consecuencia, a una consideración tanto de los supuestos mismos de la moral, como de sus medios de expresión y la manera en que unos y otros interactúan. Así, tanto los problemas de justificación del contenido de los enunciados normativos como el análisis de los enunciados mismos son, por lo general, los grandes problemas de las teorías metaéticas.

El constructivismo ético, en este contexto, puede ser entendido ya como una teoría ética sustantiva ya como una teoría metaética. Sin embargo, es a propósito de la metaética que su propuesta intenta diferenciarse de otras tendencias como el realismo (en sus diferentes versiones), el emotivismo y el naturalismo. Ahora bien, el constructivismo ético, considerado como teoría metaética, se distingue de otras teorías básicamente por dos características. En primer lugar, por intentar justificar los principios y normas morales desde un determinado "punto de vista de la razón práctica". En términos muy generales esto significa que "el punto de vista práctico es el punto de vista empleado por cualquier criatura que, en último término, considera algunas cosas en el mundo como buenas o malas, mejores o peores, imprescindibles u opcionales, valiosas o disvaliosas, etc., el punto de vista de un ser que juzga, sea en un nivel reflexivo o no reflexivo, que algunas cosas son requeridas, demandadas, o entrega razones para otras. La afirmación es que nosotros tenemos un entendimiento de dicha actitud incluso si aún no tenemos una comprensión de lo que es el valor en sí mismo" 5 . De acuerdo con esta característica no es posible hablar de hechos morales con prescindencia de una razón práctica que los valora desde una perspectiva previa a su calificación como tales.

La segunda característica del constructivismo ético es su apelación a un procedimiento de construcción de los principios y normas morales. En efecto, tradicionalmente el constructivismo ético se asocia también a la idea de un "procedimiento que pretende la construcción de una objetividad normativa (esto es constructa, no descriptiva) mediante la interacción lingüística y social de un grupo de discusión que delibera cooperativamente bajo condiciones selectas de competencia e imparcialidad en los interlocutores"6. De modo tal que "la idea central del constructivismo ético es que los juicios morales se justifican sobre la base de presupuestos

estricto rigor, ni lo uno ni lo otro, aun cuando pueda tener puntos significativos de contacto con dichas ideas. Ver a este respecto a Gómez, Carlos (2007) "El Ámbito de la Moralidad: Ética y Moral”, en La Aventura de la Moralidad, C. Gómez y J. Muguerza (eds.). Madrid: Alianza Editorial, Cap. I.

5 STREET, Sharon (2010) "What is Constructivism in Ethics and Methaethics", in Philosophy Compass 5/5, p. 366.

6 Rubio Carracedo, José (1992) Ética Constructiva y Autonomía Personal. Madrid: Editorial Tecnos, p. 250. 
procedimentales y aun tal vez sustantivos, de esta práctica social en cuyo contexto se formulan"7.

Desde esta segunda perspectiva, las ideas presentes en el constructivismo ético son: existencia de un procedimiento deliberativo (que, por una parte, establece condiciones apropiadas de deliberación y, por otra, determina las reglas de competencia de las partes involucradas en el procedimiento) y la noción de una objetividad normativa como constructo ${ }^{8}$.

\section{2.) Procedimiento DELIBERATIVO Y ObJETIVAD NORMATIVA}

\subsection{1.) Procedimiento deliberativo}

Un procedimiento deliberativo es, en este contexto, una determinada ordenación secuencial de reglas, restricciones y supuestos que tiene como objetivo resolver, mediante la organización de los términos de la discusión, una cuestión (en nuestro caso ética) controvertida entre individuos que buscan una solución racional y razonable para todos. En relación a su objeto (construcción de una objetividad normativa), dos de sus principales características son: el carácter condicionante de los términos mediante los cuales limita la discusión y la independencia de su producto (principios y normas resultantes de la deliberación) en relación al problema específico a ser resuelto por la discusión constructivista. Todo procedimiento deliberativo, en efecto, tiene un carácter condicionante respecto de los términos de la discusión, en cuanto el diseño y los presupuestos del mismo constrińen el resultado desde el inicio de la deliberación. La independencia entre el producto del procedimiento deliberativo y los problemas concretos a ser resueltos por él, a su vez, supone que el procedimiento elegido como dispositivo de deliberación es apto para ser aplicado a diferentes problemas de similar naturaleza: el procedimiento, así entendido, deviene en método resolutivo.

Desde una perspectiva constructivista, con todo, es el carácter condicionante del procedimiento deliberativo el que reviste especial importancia. En tal sentido, es propio de las teorías éticas constructivistas introducir en el diseño del procedimiento ciertas reglas, restricciones y supuestos que permiten una discusión en términos argumentativos "selectos". Ahora bien, algunas teorías constructivistas ponen un especial cuida-

\footnotetext{
Nino (1989) 11.

La idea de "objetividad" (aunque no normativa) como criterio de evaluación de la realidad no es privativa de la ética constructivista. En efecto, en el campo de las ciencias empíricas hace ya algunos años que esta noción cobra fuerza en oposición a la de "verdad" (entendida como adecuación del intelecto a una cosa). Véase a Maturana, Humberto (1997) La Objetividad, Un Argumento para Obligar. Santiago: Editorial Universitaria; y a WaLlner, Fritz (1994) Ocho Lecciones de Realismo Constructivo. Valparaíso: Ediciones Universitarias de Valparaíso.
} 
do en la determinación de las "reglas de discusión" (reglas de jurisdicción, oportunidad, competencia, clausura, etc.) ${ }^{9}$. Otras, en cambio, enfatizan la necesidad de establecer restricciones formales y supuestos de discusión antes que "reglas" (las teorías contractualistas pueden servir para ilustrar esta orientación constructivista). En todo caso, esas reglas o esas restricciones formales, o una combinación de ambas, en su conjunto, permiten en el marco de una teoría constructivista asegurar condiciones selectas de discusión que, si logran su cometido, garantizan una discusión imparcial entre individuos competentes que, a la luz de argumentos racionalmente evaluados, pueden arribar a una solución aceptable para todos.

Pero para que un procedimiento de deliberación, como mecanismo de solución de controversias, sea posible, es necesario introducir algunos supuestos adicionales a las reglas o restricciones formales de la discusión; estos supuestos, que pueden ser tanto sustantivos como formales, en todo caso, no implican necesariamente una determinada valoración moral. Dentro de estos supuestos ocupan un lugar de primer orden los relativos a los sujetos que participan en el procedimiento. En este sentido las teorías constructivista introducen el supuesto de que los individuos que participan en un procedimiento deliberativo de naturaleza cooperativa, por una parte, tienen la capacidad de participar en esa forma de interacción y, por otra, están en condiciones de explicitar frente a los demás las razones que los llevan a optar por un determinado curso de acción y no otro. La capacidad de interacción es lo que los hace "competentes", es decir, portadores de ciertas facultades que permiten la coordinación y cooperación con otros individuos. En el caso más general la competencia viene dada por cierta racionalidad, pero en esquemas de cooperación más restringidos, la competencia puede, por una parte, circunscribirse a habilidades o conocimientos más específicos (la participación en un comité de expertos en física teórica exige algo más que la mera racionalidad de sus participantes), y, por otra parte, exigir algo más que la simple racionalidad de los individuos a fin de asegurar un procedimiento propiamente cooperativo y serio (una determinada capacidad moral mínima, por ejemplo).

Pero además de la capacidad de interacción, el constructivismo ético supone que los individuos (en razón de la idea de cooperación supuesta en el procedimiento) han de estar dispuestos a dar cuenta de manera pública de las razones que avalan la adopción de una norma o principio como solución de un problema ético. Estas razones expresan tanto el fundamento del curso de acción elegido como los criterios empleados en el proceso deliberativo. Así pues, en el contexto de una teoría constructivis-

Para un examen atento sobre las posibles reglas de organización de una discusión dentro de un procedimiento deliberativo, véase Alexy, Robert (1989) Teoría de la Argumentación Jurídica. Madrid: Centro de Estudios Constitucionales. 
ta, para que la justificación del producto de la deliberación sea efectiva se requiere que cumpla ciertas exigencias de "publicidad", de modo que los fundamentos y criterios empleados en la deliberación sean conocidos por quienes toman parte en ella. En otros términos, las partes en un proceso de deliberación sobre cuestiones éticas han de tener acceso y conocimiento, entre otras cosas, a los principios morales que gobiernan a los individuos e instituciones sociales y a los fundamentos que pueden esgrimirse en favor de tales principios, a los principios alternativos susceptibles de proponerse, junto con las razones que pueden alegarse en favor de ellos, y a los conocimientos sociales generales que forman el acervo cultural común y a los comúnmente reconocidos conforme al estado actual de la ciencia, etc.

En consecuencia, desde el punto de vista de una teoría constructivista, en un procedimiento deliberativo la discusión ha de tener lugar entre individuos competentes dispuestos a justificar públicamente sus respectivas posiciones bajo condiciones selectas de argumentación. Si el procedimiento es el adecuado, el producto del mismo ha de ser considerado por los intervinientes como la solución correcta del problema propuesto en tanto expresa un principio o norma objetiva.

\subsection{2.) La idea de objetividad normativa como intersubjetividad}

Las teorías constructivistas ponen en juego una interpretación de la idea de normatividad. La idea de "objetividad normativa" cimienta, en este contexto, la posibilidad de establecer normas de acción válidas para toda la comunidad con independencia de los intereses individuales de cada cual. Objetividad significa aquí corrección de una norma o principio en razón de su génesis o construcción. En consecuencia, para el constructivismo ético, una norma (o un principio) es objetiva en la medida en que prescribe una conducta que se considera correcta por haber sido sancionada públicamente por un conjunto de individuos competentes en un procedimiento de deliberación diseńado para tal efecto. Esto quiere decir que para el constructivismo ético no tiene sentido hablar de lo "objetivo" antes del procedimiento de construcción de la norma: la objetividad es resultado del procedimiento.

A su vez, la competencia de los individuos que participan en el proceso deliberativo y decisorio, unida a la pretensión de universalizar la solución acordada en razón de su corrección y efectividad a través de la explicitación de las razones tomadas en consideración en el procedimiento resolutivo (publicidad) conforman la idea de "intersubjetividad". Vale decir, "la intersubjetividad o racionalidad consensuada engloba dos componentes estructurales, uno primordialmente de contenido y otro primordialmente de forma, que la constituyen conjuntamente. El componente 
estructural de contenido es la competencia o racionalidad práctica; el componente estructural formal es la imparcialidad o justificación pública; el primero determina los criterio de evaluación moral; el segundo, las condiciones de su aplicación" 10 .

En consecuencia, para el constructivismo ético la "objetividad normativa" deviene en "validez intersubjetiva" propiciada por un correcto diseño de procedimiento. Ahora bien, cómo deba articularse el procedimiento, justificarse la decisión y hacerse público su contenido es algo que varía de una teoría constructivista a otra. Sin embargo, el desplazamiento del discurso ético al campo de la intersubjetividad supone para la teoría constructivista en general, por una parte, tomar distancia metodológica respecto a otras ramas del conocimiento cuyo objeto de estudio sean ya los hechos empíricos (ciencias factuales), ya las realidades suprasensibles (ciencias teóricas, éticas realistas y metafísica), y, por otra, trasladar la discusión ética del campo de la "verdad" moral al de la "justificabilidad" o "razonabilidad" de los juicios morales. Esto último, en todo caso, requiere una cierta aclaración.

El constructivismo rechaza las posiciones éticas realistas, que afirman la existencia de hechos morales con prescindencia de los conceptos y concepciones mediante los cuales estos se captan y, por lo mismo, sustentan una idea de verdad entendida en términos de adecuación de los conceptos y concepciones morales a los hechos morales independientes. Para el constructivismo, las éticas realistas, en materia de justificación, están desde el inicio condenadas al fracaso debido a que desconocen, por lo menos, cuatro aspectos fundamentales de la moral.

Primero, que la determinación de los conceptos normativos no puede reconducirse a juicios meramente descriptivos. La razón de esto es simple: la descripción de una acción como valiosa, incluso vinculada a un valor independiente de la razón, nada dice respecto a la existencia misma del valor supuesto ni al vínculo obligatorio entre la idea y la acción. Frente a ello, el constructivismo, ético sostiene que los conceptos normativos no son "nombres de objetos o hechos o componentes de hechos que podamos encontrar en el mundo. Ellos son los nombres de las soluciones de problemas, problemas a los cuales damos nombre para identificarlos como objetos del razonamiento práctico"11. En este sentido, "necesitamos concepciones sobre lo correcto y lo bueno antes de saber cómo aplicar los conceptos. Así, la tarea de la filosofía práctica es la de movernos desde los

Rubio Carracedo, José (1987) El Hombre y la Etica. Barcelona: Editorial Anthropos, p. 296.

11 KorsgaArD, Christine M. (2003) "Realism and Constructivism in Twentieth-Century Moral Philosophy", in Philosophy in America at the Turn of the Century, APA, Centennian Supplement to Journal of Philosophy Research, Charlottesville, V.A., Philosophy Documentation Center, p. 116. 
conceptos a las concepciones, mediante la consideración del problema reflejado en el concepto que indicará, a su vez, la manera en que la concepción resuelve el problema. Producir una consideración constructivista de lo correcto y lo bueno es preguntar: ¿hay alguna característica del problema mismo, o de la función indicada por el concepto que pueda mostrarnos su solución?" 12 . Por esta razón, la justificación de principios y normas morales no pasa nunca por la determinación de los criterios de evaluación de una acción, sino más bien por la determinación de los principios constitutivos del razonamiento práctico, a los cuales se arriba mediante el señalamiento de los problemas éticos mismos. En otras palabras, no se pueden justificar los principios morales recurriendo a criterios de evaluación de las acciones, porque esos criterios o son los principios morales mismos o se justifican aplicando dichos principios.

Segundo, el realismo ético no repara en el hecho evidente de que los "juicios morales no se justifican en el vacío sino en el contexto de la práctica social del discurso moral que tiene presupuestos estructurales adaptados a sus funciones sociales"13. Esto significa que la valoración de un hecho cualquiera como "ético", supone una preconcepción del mismo dentro de un determinado contexto.

Tercero, en íntima relación con lo anterior, "a diferencia de las morales realistas, ellas -las éticas constructivistas- dudan o niegan que haya hechos o propiedades moralmente distintivas, naturales o no naturales, tales que puedan ser descubiertas o intuidas y proporcionar fundamentos para la ética"14; el constructivismo ético rechaza así la idea de que existan "hechos morales" independientes de la valoración intersubjetiva de los individuos y, por lo mismo, no existe una identificación de las ideas de "verdad" y "rectitud". Por las dos razones precedentes, una de las ventajas que ofrece el constructivismo ético es que "la elección de principios puede ser reconocida por los agentes como el producto de sus propias acciones, y por tanto, ellos están más inclinados a respetarlos" ${ }^{15}$. Adicionalmente, algunos han reparado, a propósito de este punto, que las teorías éticas realistas no advierten con suficiente claridad la distinción entre preguntas de naturaleza "ontológica" y preguntas de tipo "deontológico". En efecto, una cuestión es preguntar por la existencia de un valor y afirmar dicha existencia y otra cosa muy diferente es reparar en las condiciones que debe reunir un enunciado para ser considerado verdadero o válido dentro de un sistema de significado. Esta deficiencia lleva al realismo ético a con-

\footnotetext{
12 Korsgand (2003) 116.

13 Nino (1989) 11-12.

14 O’Neil, Onora (2003) “Contructivism in Rawls and Kant”, The Cambridge Companion to Rawls, Edited by S. Freeman. New York: Cambridge University Press, p. 348.

15 Graham, Paul (n/d) Rawls. Glasgow: Oneword Publication, p. 35.
} 
fundir las cuestiones de existencia con las de validez y le impide independizar el concepto de objetividad normativa del de verdad descriptiva ${ }^{16}$.

Cuarto, finalmente, las teorías realistas no ofrecen ningún procedimiento decisorio para la resolución de los conflictos éticos, pues la mera intuición de principios, incluso en el caso de ser posible, no indica nada respecto a su aplicación y prelación en el caso de un conflicto determinado o de un problema entre los mismos principios ${ }^{17}$.

\section{a. Intersubjetividad constructiva y verdad}

Pero decir que el constructivismo ético no tiene como objetivo la búsqueda de verdades morales independientes de la construcción por él propuesta, dado que la calificación de un hecho como "ético" depende de aquella y no de una propiedad inherente al hecho mismo, no significa que la verdad no juegue algún papel en la teoría. En efecto, en las teorías constructivas la idea de verdad tiene importancia en un doble aspecto: primero, a propósito de los enunciados derivados de la "teoría moral" y, segundo, a propósito de los conocimientos generales introducidos en la teoría como supuestos condicionantes del procedimiento.

\section{b. Verdad y conocimiento de la teoría moral}

En el primer aspecto, si por teoría moral entendemos el "estudio de concepciones morales sustantivas, esto es, el estudio de cómo pueden articularse las nociones básicas de lo recto, lo bueno y lo moralmente valioso formando diferentes estructuras morales" 18 , sus enunciados pueden discutirse desde el punto de vista de la verdad, considerando

Véase a STIEB, James A. (2006) "Moral Realism and Kantian Constructivism" in Ratio Juris, Vol. 19, no 4, pp. 403-405.

17 El siguiente pasaje (referido en concreto a la justicia) puede ser ilustrativo para distinguir con claridad el espíritu que anima al constructivismo ético y que lo diferencia de las teorías realistas. "El segundo modelo (se refiere al constructivismo) es muy diferente. No trata las intuiciones de justicia como indicios de la existencia de principios independientes, sino más bien como rasgos estipulados de una teoría general aún por construir, como si un escultor se propusiera esculpir el animal que mejor se adecue a una pila de huesos que ha encontrado casualmente. Este modelo 'constructivo' no supone, como el modelo natural, que los principios de justicia tengan ninguna existencia fija y objetiva, de modo que las descripciones de tales principios deban ser verdaderas o falsas de alguna manera estándar. No supone que el animal que hace coincidir con los huesos exista realmente. Establece el supuesto, diferente y en cierto sentido más complejo, de que hombres y mujeres tienen la responsabilidad de organizar los juicios particulares en un programa de acción coherente o, por lo menos, que ése es el tipo de responsabilidad que tienen los funcionarios que ejercen el poder sobre otros hombres". Dworkin, R., Los Derechos en Serio. Barcelona: Editorial Ariel, p. 247.

18 Rawls, John (1999) "The Independence of Moral Theory", Collected Papers, Edited by S. Freeman, Harvard University Press, Massachusetts, 1999, p. 286. En adelante se citará esta obra como IMT. Existe traducción castellana de la obra por M. A. Rodilla, en RawLs, John (1986) Justicia Como Equidad. Madrid: Editorial Tecnos. 
la adecuación de estos a las nociones pertinentes de las diferentes concepciones morales de las cuales trata. El tema en este caso se ha desplazado desde la consideración epistemológica de la "verdad de una teoría moral determinada" a "la verdad de un enunciado respecto a la teoría en estudio". En este sentido, dentro del constructivismo moral se pueden considerar verdaderas las aserciones teóricas respecto a la teoría misma (lo que los teóricos afirman respecto a una determinada concepción ética constructivista), cuando dan efectiva cuenta de ella. Pero, además, también comportan verdad en la teoría constructiva los juicios y normas que se derivan de la aplicación de los primeros principios construidos por ella ${ }^{19}$. En este segundo aspecto (la verdad de los juicios y normas derivada de la aplicación de los principios de la teoría) el problema de la verdad se ha desplazado desde la consideración general de la verdad sobre hechos morales independientes de toda teoría a la consideración de hechos morales en un sistema autocontenido de significado.

\section{c. La verdad de los hechos en las teorias éticas constructivistas}

Más interesante resulta el segundo aspecto de la idea de verdad en las teorías constructivistas, esto es, la apelación a la verdad de algunos de los supuestos de construcción de la teoría. Nunca en una teoría constructivista todo es construido. Por lo pronto no lo es el problema mismo que se trata de resolver mediante el procedimiento. En relación con este punto el constructivismo ético "se plantea siempre como un intento de resolver discursivamente un conflicto real de intereses, o un dilema práctico que puede ser tanto intrasubjetivo como intersubjetivo" 20 . Este conflicto "real", además, las más de las veces, supone tener que adoptar una decisión que discurre más allá del ámbito dicotómico de lo simplemente "bueno" o "malo", pues los problemas éticos transitan generalmente "entre dos bienes relativos, o entre dos cursos de acción alternativos, cada uno de los cuales contiene sus pros y sus contras" 21 , y que, por lo mismo, demandan de la teoría "la búsqueda cooperativa para construir la norma legítima y válida, esto es, capaz de solucionar el conflicto o dilema a la vez de forma correcta (justificable) y eficaz" 22 .

Pero además del "conflicto real" en la teoría constructiva está la cuestión del material sobre el que se diseña el procedimiento. En el caso que

\footnotetext{
19 "Los juicios particulares y las normas secundarias pueden ser considerado verdaderos cuando se siguen o son aplicación acertada de primeros principios razonables”. RawLs, KC., 355. Rubio Carracedo (1987) 251.

Rubio Carracedo (1987) 251-252.

Rubio Carracedo (1987) 251.
} 
estudiamos: personas cooperativas y deliberantes que pueden razonar de manera competente y asumir cierta imparcialidad a la hora de resolver un problema. Este "material" tampoco es construido por la teoría. "Debemos disponer de algún material previo con el que empezar. En un sentido más literal, sólo se construyen los principios sustantivos que determinan el contenido de lo políticamente correcto y la justicia [...] El procedimiento mismo simplemente se fija como punto de partida las concepciones básicas de la sociedad y la persona" 23 . En consecuencia, estas concepciones básicas de la "persona" y la "sociedad" son tomadas por las teorías constructivistas como un material dado. Sin embargo, aquí hay dos elementos que diferenciar. Por una parte, está la posible comprensión de la realidad mediante enunciados asertivos que expresan cierta verdad (conforme al estado del conocimiento científico) y, por otra, ciertas concepciones socioculturales que son tenidas en un contexto dado como "ideas básicas". El primer aspecto corresponde al ámbito de la ciencia y a nivel de una teoría ética constructivista entra en la discusión bajo la noción de "hechos generales" que los individuos pueden introducir en la discusión y que admiten ser evaluados conforme a criterios de verdad. El segundo aspecto se refiere, por el contrario, a ideas normativas ampliamente compartidas en una comunidad políticamente organizada. Estas ideas operan como "nociones básicas" respecto de las cuales no tiene aplicación el discurso científico, sino el ético (juicio deontológico). Desde una perspectiva constructivista son estas las ideas que se consideran dadas a la teoría.

Ahora bien, estas "ideas básicas" solo se relacionan indirectamente con la idea de verdad. De ellas no puede predicarse verdad o falsedad, pero tienen que ser compatibles con la realidad. En este sentido no tiene que haber una oposición necesaria entre ellas y los "hechos generales" conforme al estado actual de la ciencia. En tal sentido la comprensión de ciertos hechos generales relevantes $-v$. gr. a propósito de la sociedad en general y de la naturaleza humana en particular- bien puede precisar (pero no establecer) el sentido y alcance de las ideas básicas de un grupo social, y de esta forma la verdad de las proposiciones descriptivas sobre los hechos, allende a la teoría moral y conforme al estado de la ciencia, entra en el constructivismo ético solo como un elemento más de juicio ${ }^{24}$.

Rawls, John (2005) Political Liberalism (Expanded Edition), New York: Columbia University Press, p. 104. En adelante se citará esta obra como PL.

24 No han faltado los autores que han intentado una explicación pragmática del constructivismo ético mediante la cual intentan salvar la distancia que media entre una teoría de naturaleza deontológica y los "hechos", sean estos naturales o sociales. En tal sentido, Michael Buckley recientemente ha afirmado la necesidad de distinguir entre un "constructivismo basado en concepciones" de un "constructivismo basado en problemas". Mientras el primero tiene una naturaleza deontológica de base deductiva, pero no están en condiciones de justificar sus ideas base (las nociones que se incorporan a una determinada concepción del sujeto moral, la sociedad, etc.), el segundo (el constructivismo basado en problemas) tiene un 


\section{3.) ETAPAS DEL PROCEDIMIENTO ÉTICO CONSTRUCTIVO}

Hasta el momento hemos realizado una caracterización del llamado "constructivismo ético", resaltando algunas de sus notas relevantes, y lo hemos distinguido de otras concepciones éticas, específicamente de las de tipo realistas. Ahora, procederemos a delinear de manera general las etapas que es posible distinguir en un procedimiento constructivista en ética.

En términos generales, en un procedimiento ético constructivista se pueden distinguir con claridad dos etapas: una primera etapa de identificación de los problemas a ser resueltos mediante la aplicación de un procedimiento constructivista, y una segunda etapa de construcción de principios y normas propiamente tal. Sin embargo, las teorías constructivas reconocen que esas dos etapas suponen un punto de partida que propiamente está fuera de la teoría pero supuesto por ella: el mundo social, ya sea que este se exprese mediante un cierto lenguaje dado o mediante ciertos supuestos preestablecidos. Por ello, antes de centrar nuestra atención en las etapas de construcción y contraste conviene que reparemos en la idea de "mundo social" como material dado de construcción para las teorías éticas constructivistas.

\subsection{1.) El mundo social como punto de partida del procedimiento de construcción}

En las teorías constructivas, el punto de partida lo proporciona el mundo social. Éste es anterior a la construcción y, entre otras cosas, está constituido por normas. Este ámbito de acción se identifica con la noción

carácter justificativo de los elementos incorporados en una concepción al hacerlos derivar de una base pragmática como puntos de solución probable de problemas empíricamente advertidos. Así, "por una parte tenemos una investigación normativa, la cual no contiene ningún elemento interno de justificación sino, en vez de aquello, desarrollos idealizados de concepciones de la persona que están, por tanto, modelados dentro de un hipotético procedimiento de elección desde los cuales son elegidos los principios. Y, por otra parte, tenemos investigaciones sobre el problema que identifican, mediante razones, ciertos asuntos de interés público, los cuales son, entonces, articulados como criterios de evaluación contra los cuales las investigaciones normativas son valoradas. Así, si la teoría normativa falla en encontrar el criterio (de solución), ella es inapropiada y así injustificada" (Bukley, Michael (2010) "The Structure of Justification in Political Constructivism" in Metaphilosophy, Vol. 41, No 5 p. 681). Este razonamiento parece confuso en dos puntos. En primer lugar, no son los problemas y sus componentes empíricos los que determinan la moralidad de una acción, sino el razonamiento práctico que intenta resolver un problema ético no fáctico. En segundo lugar, una cuestión es la justificación constructivista de principios y normas, y otra diferente, la contrastación de tales principios con la realidad, cuestión más bien vinculadas a los problemas de la estabilidad que pueden generar en un contexto cultural en curso tales principios y normas, pero que nada dice sobre su corrección o incorrección. 
de mundo de la vida (Lebenswelt) de Habermas ${ }^{25}$ y la idea de "background culture" de Rawls, por ejemplo.

El hecho de que se suponga cierta normatividad previa como punto de partida del diseño constructivista (una normatividad que en la teoría de Rawls entra a través de ciertas "ideas básicas" sobre la sociedad y los ciudadanos) ha dado pie a que la teoría sea acusada de "circularidad", en cuanto que para la prueba de sus principios y normas recurre precisamente a aquello que pretende justificar, es decir, a principios y normas ya contenidas en la sociedad. Sin embargo, esto supone una pobre comprensión del razonamiento constructivista. En efecto, en primer lugar, lo que la teoría demuestra es que "procedimentalmente" se puede arribar a determinados principios y normas que son congeniales con cierta sensibilidad social. Con ello no se afirma que esos principios sean solo un reflejo del acervo cultural común en el cual son concebidos, sino más bien que son el criterio de comprensión y evaluación de dicho trasfondo, con el que mantiene una relación crítico-reflexiva. Porque, en segundo lugar, por regla general las teorías constructivistas no adoptan las ideas normativas básicas del trasfondo social como elementos no susceptibles de evaluación y crítica. Esto explica por qué, por ejemplo, Rawls, en el desarrollo de su teoría, establece como criterio de aceptabilidad de la misma lo que él denomina un "equilibrio reflexivo pleno", que se traduce en un consenso general alcanzado en el ámbito de la discusión pública de los presupuestos del background culture. En este escenario quien participa en el procedi-

25 En Habermas la idea de "mundo de la vida" cimienta el horizonte social en el cual los individuos ejercen, desde siempre, su acción comunicativa, entendiendo por tal "la interacción de a lo menos, dos sujetos capaces de lenguaje y de acción que (ya sea con medios verbales o con medios extra verbales) entablan una relación interpersonal. Los actores buscan entenderse sobre una situación de acción para poder así coordinar de común acuerdo sus planes de acción y con ello sus acciones. El concepto aquí central, el de interpretación, se refiere primordialmente a la negociación de definiciones de la situación susceptible de consenso. En este modelo de acción el lenguaje ocupa, como veremos, un puesto prominente". HABermas, Jürgen (1988) Teoría de la Acción Comunicativa, Tomo I. Madrid: Editorial Taurus, p. 124. Ahora bien, el llamado "mundo de la vida" no agota el espacio social, ni siquiera define enteramente lo social. En efecto, "la concepción de la sociedad como mundo de la vida, que es la que más obvia resulta desde la perspectiva conceptual de la acción orientada al entendimiento, sólo tiene un alcance limitado para la teoría de la sociedad. Por eso voy a proponer que entendamos a la sociedad simultáneamente como sistema y como mundo de la vida". Habermas, Jürgen (1988) Teoría de la Acción Comunicativa, Tomo II. Madrid: Editorial Taurus, p.168. Con todo, el concepto de mundo de la vida, esto es, el "horizonte en que los agentes comunicativos se mueven 'ya siempre' queda, por su parte delimitado en conjunto por el cambio estructural de la sociedad y cómo se transforma a medida que se produce ese cambio". Habermas (1988) t. II, 169. Como puede observarse, el "mundo de la vida" en tanto trasfondo de la acción comunicativa (que es la decisoria para la ética) se presenta como un ámbito preestablecido, pero modificable por la práctica del discurso mismo. Por así decirlo, hay una especie de diálogo entre las estructuras del "mundo de la vida" y "la acción comunicativa" que hace posible que las estructuras de uno y otra sean a la vez flexibles y modificables. 
miento deliberativo debe estar dispuesto incluso a poner en cuestión el propio acervo cultural del cual emergen las ideas normativas básicas de las que se sirve la teoría.

\subsection{2.) Identificación del problema y selección del método resolutivo}

Situados en este punto de partida social, pasamos a la fase de construcción. Los pasos de la misma son, por una parte, la identificación de ciertos hechos como problemáticos desde la perspectiva de la ética y, por otra, la adopción de un método de resolución de los mismos desde una perspectiva valorativa. Nuevamente aquí es tentador calificar la teoría de "circular", pues la identificación de un problema y la elección de un método resolutivo, a partir de un esquema social dado, presupone cierto enjuiciamiento normativo que, sin embargo, queda allende la construcción misma. Este problema no ha pasado inadvertido a la teoría constructivista; pero la respuesta a él depende en gran medida del enfoque constructivista particular de cada autor ${ }^{26}$.

Dejando de lado en este estudio la objeción precedente, es posible distinguir en la fase de construcción, una vez identificado el problema, dos etapas. La primera de ellas, como indicamos hace un momento, se refiere a la identificación de los problemas a ser resueltos mediante la aplicación del método constructivista. En este contexto, no todo problema exige una respuesta constructivista, pues muchas veces la solución a una cuestión ética pasa simplemente por la aplicación de normas morales vigentes en el sistema, sin poner en tela de juicio los principios que subyacen a las mismas. Si bien se lo piensa, esta primera etapa no es propiamente constructivista, pero es previa y demarcatoria del ámbito de la construcción ética; pues solo en la medida en que el conflicto persiste tras esta primera etapa es razonable pasar a una fase de construcción propiamente tal.

En la etapa de construcción (segunda etapa) se opta por un modelo de procedimiento, que puede ser tanto de diseño de condiciones de deliberación conjetural como de señalamiento de reglas ideales de discusión. El común denominador de ambos modelos es, en todo caso, la considera-

26 Para el constructivismo rawlsiano, por ejemplo, el problema se circunscribe a la determinación de los eventuales conflictos que se suscitan en una sociedad democrática y los valores a ella asociados, específicamente los referidos a la libertad e igualdad de las personas (vid. en este sentido KC p. 305). La cuestión es determinar de qué forma es posible justificar una concepción de la justicia que sea congenial con la idea de ciudadanos libres e iguales que participan en un esquema social de cooperación equitativa que demanda para su estabilidad un entendimiento público y adecuado de sus miembros. Todas estas ideas, claro está, forman parte de la cultura política pública de un régimen democrático constitucional, y respecto de ellas Rawls no pretende ninguna justificación constructivista, sino simplemente tomarlas como un punto de partida para la construcción de la teoría. 
ción de la realidad social como un todo complejo de interacción humana en el que se presenta un conflicto de intereses intersubjetivo que demanda una solución cooperativa de los implicados.

En el primer caso -esto es, el diseño de un escenario conjetural de deliberación- el énfasis está puesto en la determinación de las condiciones que han de informar el procedimiento deliberativo: descripción de la naturaleza de los intervinientes, reglas de deliberación, límites impuestos a la discusión y delimitación del objeto de la misma. Una vez articulado el procedimiento y obtenidos los resultados se evalúa su viabilidad en el mundo real. Las teorías contractualistas ofrecen un buen ejemplo de esta opción. El segundo modelo, en cambio, pone énfasis en la especificación de condiciones ideales de discusión a las que está sujeto el procedimiento de deliberación. Para tal efecto, se empieza dotando a las partes en conflicto de un lenguaje depurado de ambigüedades. Hecho lo anterior, las partes discuten en un escenario ideal sin ningún tipo de constricción, salvo la de argumentar racionalmente con el fin de evaluar posteriormente el escenario social real en que se mueven a la luz de las conclusiones a las que hayan arribado en el esquema ideal. El enfoque de la Escuela de Erlangen ${ }^{27}$ va por esta línea de investigación.

Vinculada a los nombres de Lorenzen y Schwemmer, la Escuela de Erlangen propone una metodología constructiva en el ámbito de la ética que busca la corrección lógico-metodológica de los enunciados normativos en una consideración crítica de los mismos. A fin de lograr su cometido aboga por la construcción de un lenguaje normativo depurado de las cargas semánticas del lenguaje ordinario, cuyo objeto es la eliminación pacífica de las controversias mediante la argumentación racional. Con todo, el punto de partida es el lenguaje ordinario que ya contiene en su seno una protoforma lógica.

Para que la ética tenga éxito es menester que los intervinientes en el discurso tengan la intención de participar en él en condiciones de seriedad. El punto de partida de esta "buena disposición" de los participantes no deriva de una corrección metafísica de su naturaleza, sino del uso de las reglas condicionadas por su resultado (imperativos hipotéticos y no categóricos). Pero ¿cómo arribar a este metalenguaje práctico? En primer lugar, se ha de comenzar por una depuración lógico formal del lenguaje. Esta depuración pasa por distinguir dentro del lenguaje un "paralenguaje" (lenguaje mediante el cual se enseña otro lenguaje), un "ortolenguaje" (lenguaje depurado de ambigüedades, cuyos términos, en clave simbólica, no tienen sinónimos). Distinguidos ambos, el asunto es proceder a la construcción de un ortolenguaje que permitirá una discusión controlable racionalmente. "Debemos, por tanto, construir un ortolenguaje que pueda ser usado en los argumentos prácticos. Si la filosofía práctica nos provee de un vocabulario mediante el cual podemos argumentar a favor o en contra de las normas, primero debe poner a nuestra disposición una terminología ortolinguística "mental". Lorenzen, Paul (1969) Normative Logic and Ethics. Mannheim: Bibliographisches Institute A.G., p. 76. En adelante se citará como Normative. En segundo lugar, se ha de analizar la génesis de las normas vigentes, pero no para trabajar con ellas como un material dado, sino con el fin de descubrir su adecuación a las circunstancias de origen y actuales y de determinar su racionalidad. Esta segunda fase supone una crítica al sistema normativo imperante (juicio racional al mismo). Lorenzen denomina a este paso la "búsqueda dialéctica". Claro que aquí la expresión "dialéctica" se usa para definir "el tipo de consideración genética que es adecuado para el análisis de problemas práctico" (Normative, p. 87). La "génesis", a su vez, es naturaleza "normativa". A esta génesis normativa se llega mediante un intercambio transubjetivo (aquel que se verifica entre individuos 


\subsection{3.) Contrastación de la teoría}

Finalmente, y fuera del procedimiento constructivista propiamente tal, los principios generados mediante este método deben hacer frente a dos cuestiones diversas: por una parte, a problemas de viabilidad y, por otra, a cuestiones de aceptabilidad de los principios propuestos por la teoría. Es decir, una vez establecidos constructivistamente los principios éticos conforme a los cuales han de evaluarse las conductas, se presenta el problema sobre si las soluciones propuestas por el modelo son susceptibles de ser implementadas en el mundo real y, en consecuencia, ser acatadas por los destinatarios de la misma. De alguna manera esta "contrastación" depende en estas teorías de la precomprensión del mundo social como un ámbito normativo. Con todo, aquí ya no se trata de una cuestión de "justificación" de los principios éticos (los cuales son justificados por el procedimiento de construcción), sino más bien, por una parte, de la adhesión a ellos, o lo que es igual de su "efectividad" y, por otra, de su aceptación por parte de los sujetos morales.

Las críticas que se formulan en este contexto a las teorías éticas constructivistas afectan a la pretensión de "universalidad" de los principios: pues si la efectividad de un principio depende de su contexto social ya no se puede hablar de una ética universal. Esta ha sido la línea de argumentación seguida por las llamadas teorías éticas "comunitaristas" en contra del constructivismo ético ${ }^{28}$.

Sin poder entrar ahora a desarrollarla con detalle, la crítica precedente nos parece desenfocada y parte de una concepción errónea del constructivismo. Está desenfocada porque el constructivismo no postula un sustrato normativo invariable o preestablecido de manera inmutable, sino referido a una realidad social dinámica, en remodelación constante precisamente por la posibilidad de una crítica racional de la misma. El cons-

conscientes de los límites de su propia subjetividad), que permite el diseño de un modelo ideal en el cual se integran todas las posibilidades (sin exclusión) de modelación de la conducta en vistas a satisfacer necesidades. Específicamente se trata de "necesidades" (needs) sociales, esto es, no naturales (alimento, comida y abrigo, por ejemplo) y elevadas a tal categoría por descarte de los "deseos subjetivos" (wants).

En tercer lugar, depurado el lenguaje y descartadas las normas irracionales, viene una etapa de "reforma cultural", esto es, de implementación de las normas debidas en razón de la efectiva solución pacífica de los conflictos. En esta teoría, la construcción de normas se identifica con un modelo de crítica de las reglas de discusión: la corrección del discurso, la crítica desde la corrección anterior a la génesis fáctica de las normas imperantes en una sociedad y, de ser necesaria, la modificación de las tales normas (cuando no se adecuan a un estándar racional) es el objetivo de procedimiento.

Para un examen más detenido del tema véase también, Alexy (1989)143-156.

28 Vid., a este respecto, a MACINTYRE, A. (1985) After Virtue (second edition). London: Duckworth; SANDEL, Michael (2000) El Liberalismo y los Limites de la Justicia. Barcelona: Editorial Gedisa; Mulhall, Stephen \& SwIFT, Adam (1996) El Individuo Frente a la Comunidad. Madrid: Ediciones Temas de Hoy. 
tructivismo ético bien entendido, por tanto, es un esfuerzo progresivo, sujeto a revisión constante y cuyo concepto de "universalidad normativa" no se confunde con el de "invariabilidad ética", pues que una norma sea universalmente válida solo quiere decir que bajo ciertas condiciones racionales ha de ser aceptada por los intervinientes en un discurso cooperativo en tanto no se ofrezcan y acepten nuevas razones que sean consideradas más acertadas para la resolución de un asunto conflictivo en materia ética. Con lo cual, en definitiva, la universalidad normativa deviene en aceptabilidad universal de ciertos principios establecidos por la razón práctica y un "procedimiento resolutivo" nomotético (también sujeto a revisión), capaz de determinar las normas que una sociedad determinada (adscrita a una tradición cultural y en un momento histórico dado) demanda para su desarrollo.

Recapitulando en líneas generales lo dicho hasta el momento, podemos señalar que el constructivismo ético se inscribe dentro de la teoría metaética caracterizándose por las ideas matrices de que, por una parte, no existen hechos morales independientes de los propios sujetos morales $y$, por otra parte, que los conflictos morales se resuelven a través de un procedimiento que, a su vez, justifica y legitima la solución adoptada. Dicho procedimiento contiene ciertos supuestos, tales como las ideas de capacidad de los intervinientes y de objetividad de la resolución del asunto controvertido desde la perspectiva de la corrección y eficacia de la respuesta ética. La capacidad de las partes supone, a su vez, la posibilidad de una solución cooperativa y consensuada a los problemas éticos; mientras que la idea constructivista de objetividad aporta autonomía a la teoría tanto respecto a otros ámbitos de la filosofía como respecto a la idea de "verdad" en el sentido fuerte de la expresión, esto es, como adecuación del pensamiento a una realidad independiente. Para la realización de su cometido, la teoría supone una serie de pasos: identificación del problema y directrices para su solución; diseño de un modelo de respuesta (procedimiento) $\mathrm{y}$, allende al procedimiento constructivista propiamente tal, la contrastación de sus resultados (los principios) con la realidad, esto es, materialización de la teoría en la práctica social en cuanto los principios propuestos puedan generar cierto grado de estabilidad social y aceptación por parte de sus destinatarios. En lo que sigue de esta investigación veremos de qué forma cada uno de estos elementos se encuentra presente, desde un particular y propio enfoque, en el constructivismo de John Rawls. 


\section{3) El CONSTRUCTIVISMO ÉTICO DE RAWLS}

Como ya se ha dicho, a partir de Kantian Constructivism in Moral Theory ${ }^{29}$, Rawls caracteriza su punto de vista ético como constructivista. Esta estrategia le permite contar con un método de justificación de la teoría coherente con los postulados de la misma. Sin embargo, aún más significativo que lo anterior, la explicitación del método contribuyó a que el autor de $A$ Theory of Justice, con el devenir de los años, tomase conciencia más clara, por una parte, de la naturaleza y el alcance de los principios de justicia mismos y, por otra, del ámbito propio de aplicación y validez del método constructivista. En tal sentido, a partir de la década de los ochenta, Rawls cinrcunscribe progresivamente su teoría de la justicia en el acotado ámbito de la determinación de principios "políticos" de justicia (como una clase específica de principios morales), y reserva el método constructivista exclusivamente para la selección de tales principios.

En la exposición que a continuación ofrecemos del constructivismo ético de Rawls, dejaremos de lado, con todo, las consecuencias que la aplicación del método tuvo para la autocomprensión de la teoría misma. Enfocaremos nuestra atención simplemente a la interpretación constructivista que el propio Rawls hace de su teoría. En primer lugar, mostraremos cómo es posible identificar cada uno de los elementos de una teoría metaética constructivista en el propio proyecto normativo de Rawls (justice as fairness). Hecho lo anterior, examinaremos la transición que experimentó Rawls desde un enfoque constructivista moral de ascendiente kantiano hacia un constructivismo político que pretende tomar distancia de Kant. Finalmente, realizaremos algunos comentarios críticos sobre la estrategia política adoptada por Rawls a propósito del constructivismo ético.

29 En este sentido, "un decisivo punto de inflexión en la trayectoria se produjo, más bien, con la publicación de las John Dewey Lectures de 1980 bajo el título "Constructivismo Kantiano en la Teoría Moral". En efecto, a partir de ese momento es perceptible en los escritos de Rawls un importante desplazamiento del centro de gravedad: desde los aspectos normativos de la teoría a los aspectos metodológicos, desde el plano del discurso práctico sobre los principios de justicia al del discurso filosófico-práctico sobre las bases de fundamentación de principios de justicia, desde la elaboración de la teoría a la autocomprensión de la misma. A decir verdad, con las Lectures de 1980 John Rawls sometió su teoría a un proceso de autorreflexión que se prolonga hasta nuestros días. Por autorreflexión entiendo aquí un proceso de discusión sobre la naturaleza y los presupuestos, las pretensiones y los límites de la teoría. Ese proceso de autorreflexión ha ido, por su parte, acompañado de una toma de conciencia cada vez más aguda sobre el modo como la intención práctica, que es constitutiva para una teoría de la justicia, tal como Rawls la entiende, afecta a la configuración interna de la teoría y a sus pretensiones epistémicas". Rodilla, M.A. (2006) Leyendo a Rawls. Salamanca: Ediciones Universidad de Salamanca, p. 82. 


\section{1.) ESBOZO DEL DISEÑo ÉTICO CONSTRUCTIVISTA DE JUSTICE AS FAIRNESS}

Conforme a las ideas constructivistas de Rawls, los principios de justicia de justice as fairness se encuentran justificados si es posible hacerlos derivar de un dispositivo de deliberación que reproduce condiciones selectas de discusión que garantizan, a quienes se sirven del mismo, su propia corrección y la de su resultado. Este dispositivo en la teoría rawlsiana recibe el nombre de "posición original" (original position). En ella se incorporan supuestos que permiten a quienes se encuentran en esta elegir principios de justicia de manera racional y razonable. Estos supuestos, por una parte, delimitan el objeto de la discusión, señalando las propiedades formales que deben reunir los principios para poder ser admitidos a discusion (the subject of justice y the formal constraints of right), y, por otra, determinan la competencia de los intervinientes (autonomy of moral persons), esto es, quiénes han de ser considerados interlocutores válidos dentro del procedimiento. La existencia de las condiciones que dan forma al procedimiento, unidas a ciertos presupuestos sobre la naturaleza humana (conception of human being) así como sobre el contexto general en el que se presentan problemas de justicia (the circunstances of justice), permiten a la teoría desarrollar la idea de "objetividad normativa" como expresión de un consenso intersubjetivo alcanzado en una comunidad de discusión cooperativa.

La objetividad normativa, así entendida, hace posible en justice as fairness explicar el fenómeno político-moral sin necesidad de recurrir a la idea de verdad (como correspondencia con una realidad independiente), toda vez que, conforme a sus directrices, no existen hechos morales allende la deliberación intersubjetiva que permite la objetividad de los principios de justicia (the ideas of the reasonable and the priority of right).

En consecuencia, mediante la aplicación del método constructivista, Rawls no persigue el descubrimiento de principios de justicia, sino la justificación de los mismos a través de un dispositivo de deliberación y elección. En tal sentido, justice as fairness parte de la realidad social como una situación dada y de naturaleza normativa. En este contexto la teoría viene a evaluar desde la perspectiva de la intersubjetividad los principios de justicia disponibles en una sociedad determinada (a democratic society) para hacer frente a los problemas morales. La evaluación de los principios de justicia y los problemas a ellos asociados, a su vez, puede redundar en la aceptación de las soluciones éticas existentes o en un cambio de perspectiva tal que suponga la formulación de nuevos principios de justicia, la modificación o el definitivo abandono de los mismos, junto a sus problemas (si resultase que estos están fuera del dominio de una teoría de la justicia). 
Justificados los principios de justicia conforme a un procedimiento constructivista, siempre se podrá, a continuación, evaluar su funcionamiento efectivo dentro de la realidad social, esto es, los principios de justicia justificados constructivamente y el dispositivo de construcción mismo pueden ser "contrastados" con las ideas normativas que forman parte del acervo cultural común de una sociedad (reflective equilibrium). Este contraste entre los principios de justicia y la realidad social hace posible, por una parte, conciliar los principios de justicia y ciertas ideas presentes en el acervo político de una sociedad democrática constitucional (reflective equilibrium attained), $\mathrm{y}$, por otra, la adecuación de las soluciones éticas a las nuevas circunstancias del entorno social desde una perspectiva dinámica y moralmente objetiva, gracias a un diálogo intersubjetivo abierto a la revisión constante de los principios de justicia imperantes en una sociedad determinada (the public reason).

\section{2.) DESDE UNA TEORÍA ÉTICA CONSTRUCTIVISTA DE ORIENTACIÓN KANTIANA HACIA UNA TEORÍA POLÍTICA CONSTRUCTIVISTA}

Las ideas precedentes son aplicables sin reserva a justice as fairness como teoría ética que intenta justificarse desde una perspectiva constructivista. Sin embargo, la forma en que tales ideas (diseño del procedimiento y naturaleza de sus elementos) fueron entendidas por Rawls a lo largo del tiempo, el peso relativo de ellas dentro del diseño del procedimiento de deliberación y la manera en que se articularon en la teoría, hace necesario distinguir dos períodos. El primero de ellos corresponde a una interpretación constructivista de orientación kantiana, mientras que el segundo período se vincula a lo que el propio Rawls denomina "constructivismo político".

\subsection{1.) Justice as fairness como teoría constructivista de filiación kantiana}

En $A$ Theory of Justice, de 1971, es posible hallar los primeros vestigios de una aproximación constructivista al problema de la elección de principios de justicia. En efecto, aunque en esta obra no se dice explícitamente que la teoría es constructivista, la verdad es que la idea implícita en justice as fairness de que lo justo es el resultado de un procedimiento "fair", unida a la noción de justicia procedimental pura, apuntan en una dirección inequívocamente constructivista que toma distancia tanto del realismo como del intuicionismo éticos. En este contexto, Rawls escribe a propósito de las diferencias de su teoría con el intuicionismo moral que "una refutación del intuicionismo consiste en presentar la clase de 
criterios constructivos que se ha dicho (por parte del intuicionismo) no existen" 30 . Estos criterios tienen por objeto superar los inconvenientes que supone la mera aprehensión de principios morales, a saber, la falta de directrices para su aplicación, la ausencia de reglas de prelación entre los mismos, etc. En otras palabras, una de las ventajas que presenta la justicia como equidad, metodológicamente hablando, es la posibilidad de mostrar desde el principio los "procedimientos" y "criterios" a seguir para la resolución de los conflictos del orden moral. "Esta visión, más bien limitada, del constructivismo destaca el sentido práctico de las teorías constructivas, que proveen criterios y procedimientos para la dirección de la acción"31. "Esta temprana y tenue concepción de la construcción ética lleva a Rawls a clasificar tanto al utilitarismo como a su posición más kantiana como constructivas: ambas se diferencian de posiciones en ética que no ofrecen criterios constructivos, y así no son, o no confiablemente, prácticas" 32 . Claro que estas primeras ideas de naturaleza constructivista todavía no especifican, por una parte, la naturaleza de una teoría metaética constructivista y, por otra, el constructivismo propio de justice as fairness.

En efecto, solo nueve años después, en Kantian Constructivism in Moral Theory, Rawls precisará con mayor detalle qué significa que una teoría ética sea "constructivista" y en qué sentido su propia teoría puede ser inscrita dentro de un tipo específico de constructivismo ético, a saber, el kantiano. Respecto a lo primero, Rawls sostiene que, conforme a una teoría ética constructivista, "que ciertos hechos hayan de contar como razones de justicia y cuál haya de ser su fuerza relativa es algo que sólo puede establecerse sobre la base de los principios que resulten de la construcción" 33 . Vale decir, no es adecuado hablar de "hechos morales" independientes de los conceptos que los establecen desde el punto de vista de la razón práctica y conforme a un procedimiento.

En Kantian Constructivism, asimismo, no solo nos advierte Rawls de que su teoría de la justicia es de naturaleza constructivista, sino además explícitamente nos dice que es una teoría moral de orientación kantiana. Esta afirmación, sin embargo, debemos tomarla con cierta reserva. A decir verdad, Kantian Constructivism transita en muchos aspectos por un derrotero no solo diferente del de la filosofía de Kant, sino incluso bastante distante de la propia interpretación que Rawls había hecho de Kant en $A$ Theory of Justice en 1971. Sin embargo, al parecer, aún en 1980 Rawls piensa que su teoría se inscribe de algún modo dentro de la tradición kantiana.

\footnotetext{
Theory Original, p. 39. El paréntesis es nuestro.

O’Neill, Onora (2003) "Constructivism vs. Contractualism”, in Ratio XVI, 4, December, p. 320 .

O’NeIll (2003) 320.

KC, p. 351 .
} 
A Rawls, la teoría moral kantiana le pareció atractiva básicamente por dos razones. En primer lugar, porque pretende dar cuenta de la génesis de una concepción moral, sus supuestos y los procedimientos incorporados en ella, al mismo tiempo que desarrolla las consecuencias que de tal concepción se derivan. En segundo lugar, a Kant le parece interesante por la primacía que adquiere en su filosofía la noción de sujeto moral a la luz de la idea de "autonomía". Es precisamente esta idea la que tiene una importancia capital en la interpretación kantiana que ensaya Rawls sobre su teoría en el parágrafo 40 de $A$ Theory of Justice. Eso sí, la visión que Rawls ofrecía allí de Kant no pretendía tanto contribuir a un mejor entendimiento de la teoría moral kantiana ${ }^{34}$, como facilitar una mejor interpreta-

34 La especial interpretación de Rawls respecto a la moral kantiana no ha estado exenta de discusión. En efecto, para algunos estudiosos falla la correlación que Rawls trata de establecer entre ciertos conceptos kantianos básicos (autonomía, imperativo categórico, reino de los fines) y sus propias nociones (persona moral representada en la posición original, principios de justicia, sociedad bien ordenada). En este sentido Andrew Levine ha sostenido que la interpretación rawlsiana adolece de graves deficiencias en cuanto a la inteligencia del pensamiento de Kant. Según él, los errores del parágrafo 40 de Theory residen en confundir, por una parte, la idea de autonomía kantiana con la de universalización y generalización de principios de conducta, en intentar, por otra parte, conciliar las ideas de imperativo categórico y principios de justicia sin considerar la génesis de uno y otros, y, finalmente, en suponer que la noción de reino de los fines es equivalente a la de sociedad informada por los principios de justicia de la justicia como equidad. En relación a lo primero, "en contra de lo que Rawls parece sugerir, el velo de la ignorancia elimina sólo el conocimiento que nos distingue de otros seres humanos; el velo remueve todos los atributos personales distintivos, dejando al descubierto, si Rawls está en lo cierto, lo esencialmente humano. Esto nos fuerza, en consecuencia, a evaluar las alternativas desde un punto de vista de la humanidad en general. Esto impone una limitación de desinterés, relativo a otras personas. En este sentido, es razonable concluir que Rawls ha proporcionado un procedimiento de reconstrucción de nuestra noción ordinaria de universalidad y generalidad" (Levine, Andrew (2003) "Rawls' Kantianism", en John Rawls, Critical Assessments of Leading Political Philosophers, Volume I, Edited by Chandran Kukathas. London: Routledge, p. 348) Sin embargo, esta noción, en estricto rigor, nada dice de la autonomía individual al modo kantiano. La autonomía kantiana es expresión única y exclusivamente de una conducta informada por la razón práctica pura (sin remisión a ninguna contingencia) y subordinada a un imperativo categórico. Pero en Rawls la idea de velo de la ignorancia coexiste con la de orientación de la acción hacia los "bienes primarios", lo que condiciona una elección motivada externamente, que, aunque universal y general, sigue siendo heterónoma. Por otra parte, tampoco cabe establecer una relación exenta de problemas entre el "imperativo categórico" y los "principios de justicia rawlsianos". Pues, "para Kant, el imperativo categórico, se aplica a las personas en virtud de su naturaleza libre y racional. Pero esta libertad y racionalidad son trascendentales e incondicionadas por cualquier fin meramente contingente, no importa cuán universalmente aceptado sea. En este sentido el imperativo categórico prescribe 'categóricamente'. En la consideración de Rawls, en cambio, el deseo de bienes primarios es parte de la naturaleza de un ser racional. En este sentido de la 'racionalidad', los principios de conducta que se aplican a nosotros en virtud de nuestra 'naturaleza libre, igual y racional' son condicionados por fines meramente contingentes; esto es, por bienes primarios" (Levine (2003) 351). En este contexto difícilmente puede decirse que el imperativo categórico kantiano guarde algo en común con los principios de justicia. Finalmente, la idea misma de "reino de los fines", conforme a la lectura de Levine, es totalmente incompatible en Kant y Rawls. "El tipo de comunidad descrita finalmente por Rawls, como quiera que él la caracterice, no es, después 
ción de su propia teoría de la justicia a la luz de la filosofía moral kantiana con la que aquella mantenía un parentesco ${ }^{35}$. Mediante esa estrategia, por una parte, la teoría quedaba inscrita en una determinada tradición filosófica y, por otra, el propio dispositivo de deliberación constructivo adoptado en la obra, a saber, la posición original, quedaba justificado filosóficamente desde la perspectiva de una de las ideas fundamentales de la moral kantiana: la noción de autonomía de los sujetos morales.

En Kantian Constructivism todavía es posible encontrar ciertos ecos del kantismo del parágrafo 40 de $A$ Theory of Justice. En tal sentido, Rawls insiste en que "lo distintivo de la forma kantiana del constructivismo es esencialmente esto: que especifica una concepción particular de la persona como un elemento de un procedimiento razonable de construcción, cuyo resultado determina el contenido de los primeros principios de justicia”36, pues de acuerdo con su interpretación el constructivismo kantiano viene a responder la pregunta de “¿cómo puede la gente decidir cuál es la concepción de la justicia que -para que sirva a su papel social- es (la más) razonable para ellos en virtud de cómo ellos conciben a sus personas e interpretan los rasgos generales de la cooperación social entre personas así consideradas?" 37.

Ahora bien, una lectura atenta de Kantian Constructivism permite ver la dirección en la que se encamina el constructivismo rawlsiano. Por una parte, se introducen ciertas correcciones a la propuesta constructivista kantiana en orden a seguir depurándola de elementos metafísicos y situarla en el contexto operativo de la decisión política. Sin embargo, también se introducen cambios en orden a circunscribir la teoría propuesta (justice as fairness) a un dominio bastante más acotado. Para tal efecto, Rawls afina los conceptos de construcción limitando su extensión en términos tales que, articulados en la posición original, sirvan única y exclusivamente para dar cuenta de los principios de justicia que demanda la estructura básica de un tipo determinado de sociedad, a saber, sociedades democráticas modernas. Eso conduce a que ciertas ideas desarrolladas en el parágrafo 40 reciban una nueva interpretación; esto ocurre en particular con la noción de autonomía moral, que ahora se aplica a los ciudadanos de un régimen político particular (el sistema democrático-constitucional) y con la idea de "sociedad bien ordenada" que pasa a ser interpretada en térmi-

de todo, el 'reino de los fines' en el sentido kantiano, en el cual las personas mantienen relaciones intrínsecas las unas con las otras, sino una asociación de egoístas racionales con valores compartidos, aunque esencialmente individuales. En esta comunidad rawlsiana, las personas mantienen estrictamente relaciones extrínsecas las unas con las otras; en el sentido kantiano se tratan las unas a las otras como medios" (Levine (2003) 354). va de Kant, sino más bien, de la justicia como equidad". Theory Rev., p. 226.

KC, p. 304.

KC, p. 305. 
nos de sociedad bien ordenada de naturaleza democrática-constitucional. De ahora en adelante, serán estas concepciones "políticas, que Rawls considera latentes en la cultura política de las sociedades democráticas, las que entrarán en la teoría constructivista como "ideas modélicas" de la misma.

En este contexto, justice as fairness tiene como propósito "tratar de descubrir las ideas fundamentales (latentes en el sentido común) de libertad e igualdad, de cooperación social ideal y de persona, mediante la formulación de lo que voy a denominar "concepciones modelo" 38 . Son las concepciones modelo de los ciudadanos como personas morales, y sociedad bien ordenada como el ideal de una sociedad efectivamente gobernada por una concepción pública de la justicia las que entran en el diseńo constructivista a través de un procedimiento de construcción que es capaz de establecer una relación adecuada entre unas y otras. Este dispositivo es la posición original.

La importancia de la posición original, como dispositivo, pretende establecer la relación adecuada entre las ideas de "ciudadano", "sociedad bien ordenada" y ciertos "principios de justicia", radica en que en ella, de alguna manera, al incorporar en su diseño ciertas restricciones formales, se reproducen las condiciones de plena autonomía que hacen teóricamente posible que las partes, "como agentes de construcción", elijan los principios de justicia más acordes a la comprensión que tenemos de nosotros mismos como ciudadanos libres e iguales de un régimen político democrático y constitucional.

En ese sentido, "las deliberaciones racionales de las partes en la posición original sirven como modo de seleccionar entre concepciones de justicia tradicionales u otras concepciones prometedoras. Así entendida, la posición original no es una base axiomática (o deductiva) de la que se deriven principios, sino un procedimiento para determinar los principios más acordes con la concepción de la persona que más verosímilmente ha de mantenerse, al menos de forma implícita, en una sociedad democrática moderna" 39 .

Finalmente, el contenido de la concepción de la justicia no deriva del punto de vista monológico de un sujeto moral trascendental, sino que en todo momento ha de entenderse "por referencia a un punto de vista social adecuadamente construido, un ejemplo del cual es el marco proporcionado por el procedimiento de la posición original" ${ }^{2}$. No estamos aquí, en consecuencia, ante un punto de vista trascendente, sino ante uno social en varios sentidos: es social pues representa el punto de vista públicamen-

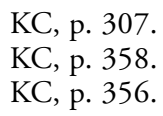


te compartido por los miembros de una sociedad bien ordenada, y los principios que desde este se eligen tienen por finalidad regular la estructura básica social que, a su vez, permite especificar los términos equitativos de cooperación social que definen a una sociedad bien ordenada ${ }^{41}$.

En resumen, a partir de Kantian Constructivism, Rawls entiende que su teoría puede ser interpretada constructivistamente a partir de las relaciones que es posible establecer entre las ideas de "persona moral" (ahora hay que entender que se refiere a ciudadanos de un determinado régimen político), "sociedad bien ordenada" (solo la sociedad democrática constitucional) y "posición original". A estas concepciones las denomina "concepciones modelo" (model-conceptions). Cada una de estas concepciones modelo está llamada a desempeñar una función en la teoría. Las ideas de "persona moral" y "sociedad bien ordenada" tienen por finalidad precisar los elementos que se entiende forman parte de la estructura social de un sistema que considera a sus miembros como personas morales libres e iguales y que, por eso, reclama una cierta regulación congenial con dichas ideas y el tipo de esquema de cooperación social que a ellas mejor se aviene. La posición original, por su parte, cumple una función de mediación en tanto que procedimiento en el que estarían representados ciudadanos llamados a elegir los principios con los que podrían bien-ordenar su sociedad. En otras palabras, la posición original representa el canal de comunicación entre las ideas de "persona moral" y "sociedad bien ordenada" haciendo posible su comunión a través de la selección de principios de justicia $^{42}$.

\subsection{2.) Justice as fairness y su justificación desde el constructivismo político}

En Kantian Constructivism están, pues, presentes los elementos principales que reclama una teoría constructivista. Sin embargo, en esa obra aún se advierte que la idea de autonomía de los sujetos morales tiene un papel preeminente. Con el tiempo, Rawls se dio cuenta con mayor intensidad de que existía una tensión entre las ideas de autonomía moral y autonomía política, y eso, unido a otras consideraciones relacionadas con las pretensiones prácticas de la teoría, lo llevó a abandonar la primera y a circunscribir su teoría metaética al acotado dominio de lo político, con lo

Vid., KC, p. 356.

"Las restricciones impuestas a las partes en la posición original, y la manera como se describe a las partes, han de representar la libertad y la igualdad de personas morales tal como se las entiende en tal sociedad. Si ciertos principios de justicia fueran en verdad acordados (o si pertenecieran a una determinada familia restringida de principios), entonces se alcanzaría la meta del constructivismo kantiano de poner en conexión principios definidos y una determinada concepción de la persona”. KC, p. 308. 
cual de ahora en adelante justice as fairness se inscribirá en el registro propio de un constructivismo político. Con ello se abre paso lo que el propio Rawls denomina "constructivismo político" 43 .

A pesar de las modificaciones y rectificaciones introducidas después de Kantian Konstructivism, se mantiene inalterado el método de construcción. Varía, en cambio, la comprensión de la propia teoría y de los elementos que se incorporan en la posición original. Por lo anterior, nos parece útil precisar qué significa concebir el método constructivista como de naturaleza política. Rawls dedica la tercera lectura de su Political Liberalism de 1993 a responder esta pregunta.

Básicamente, que la justicia como equidad sea una concepción ética constructivista de naturaleza política significa entre otras cosas: i.- que tiene por objeto la determinación de principios de justicia llamados a informar la estructura básica de la sociedad (la constitución política y las principales instituciones sociales involucradas en la distribución de derechos y obligaciones); ii.- que se presenta en el horizonte de una sociedad democrática como independiente de toda doctrina de naturaleza comprehensiva, sea esta de carácter religioso, filosófico o moral, de modo que las nociones de las que se sirve la teoría para modelar la posición original como dispositivo de deliberación son ideas latentes en la cultura política de las sociedades democráticas y expresan valores políticos de un sistema democrático constitucional (libertad, igualdad, ciudadanía) y no de valores morales generales o exorbitantes a dicho sistema político; iii.- aun cuando en ella la noción de "autonomía" (idea de claro ascendiente moral kantiano) es fundamental, el contenido de la misma se restringe al ámbito de lo político; iv.- el objetivo de la justicia como equidad, en tanto teoría ética constructivista, es hacer posible un entendimiento público en torno a principios de justicia entre ciudadanos divididos por doctrinas comprehensivas razonables; v.- la idea de objetividad normativa se circunscribe al ámbito de la razonabilidad que demanda la razón práctica de los ciudadanos de un régimen político.

Con el pasar de los años, Rawls fue progresivamente tomando conciencia de que su teoría de la justicia estaba pensada para ser implementada solo a un nivel político y en el contexto de una sociedad democrática constitucional que se desenvuelve en condiciones normales y que está además afectada de forma irreversible por el "hecho del pluralismo". Una

43 Esta etapa, pensamos, se inicia con la publicación en 1985 de "Justice as Fairness, Political not Metaphysical'. Desde este momento de manera explícita Rawls afirma que el constructivismo en el que él está pensando es de naturaleza política. En Political Liberalism de 1993, a su vez, Rawls nos indica qué significa que su teoría de la justicia sea constructivista política: "desde el inicio el ámbito del constructivismo político ha sido limitado a los valores políticos que caracterizan el dominio de lo político; éste no es propuesto como una consideración de los valores morales en general". PL, p.125. 
sociedad tal está caracterizada por considerar a sus ciudadanos como libres e iguales, pero, además, profundamente divididos por doctrinas comprehensivas, pero al mismo tiempo razonables, esto es, dispuestos a entenderse sobre los términos básicos de su asociación política a pesar de sus diferencias religiosas, filosóficas, etc. Este hecho da lugar a lo que Rawls denomina "el razonable pluralismo". En un contexto así, una teoría de la justicia que no se entienda a sí misma como una empresa meramente especulativa debe aspirar a ser capaz de concitar entre los diferentes actores sociales un grado aceptable de adhesión, considerando las diferentes cosmovisiones presente en la sociedad. Pero en las condiciones del pluralismo vigente eso será posible únicamente si la teoría limita su alcance de aplicación a la determinación de principios llamados a regular solo la estructura básica social desde una perspectiva "independiente" (free standing view) de las diferentes visiones de mundo (background culture).

La independencia de la teoría de la justicia, en cuanto concepción constructivista de carácter político, será posible en la medida en que, para suscitar el grado de adhesión que demandan sus principios, apele a ideas políticas propias de una sociedad democrática. Entre ellas, destacan las nociones de ciudadanos libres e iguales y la idea de sociedad como sistema equitativo de cooperación. Estas ideas, y los valores a ellas asociados, no son patrimonio exclusivo de ninguna doctrina comprehensiva que pueda formar parte del contexto cultural de una sociedad democrática y, sin embargo, tienen la aptitud y poder suficiente para lograr un grado de aceptación entre los diferentes actores sociales en razón de su propio mérito.

Un elemento fundamental dentro del constructivismo ético, como lo entiende Rawls, es la exigencia de autonomía de la propia teoría de la justicia. Desde un horizonte político, esa exigencia admite un sentido débil y uno profundo. En un sentido débil, que la teoría de la justicia sea autónoma significa que los principios que la definen y los fundamentos que para su adopción se entregan son de naturaleza política, independientes de doctrinas religiosas, filosóficas o morales comprehensivas. En un sentido profundo, la idea de autonomía es considerada un elemento definitorio de toda teoría constructivista de la justicia toda vez que, de acuerdo a esta, los principios de justicia llamados a informar la estructura política de una sociedad democrática constitucional son producto de la razón práctica (aunque no se trata necesariamente de una razón práctica constitutiva al modo kantiano). Los principios son el producto de una construcción ${ }^{44}$ y no el resultado de un descubrimiento de verdades allende al

Con todo, esta idea profunda de autonomía no está exenta de problemas. En efecto, "muchos autores han enfatizado el hecho de que hay algo altamente desconcertante e inusual en el método de Rawls que el dispositivo del contrato social tiende a ocultar, esto es, que en el corazón de la teoría hay una 'doctrina profunda' no explícita sobre la autonomía y el igual 
procedimiento; lo que no impide que ellos puedan coincidir o expresar principios morales más generales afirmados por doctrinas comprehensivas no constructivistas.

Una teoría de la justicia políticamente constructivista, que se presenta ante los ciudadanos como independiente de las diferentes doctrinas comprehensivas razonables (pero compatibles con ellas) y como políticamente autónoma (en cuanto a sus principios y fundamentos), tiene como principal cometido establecer las bases de un entendimiento público en torno a la concepción de la justicia más adecuada para el régimen político en el que se desarrolla. No busca, en consecuencia, lograr la unidad de la razón de un yo trascendental que unifica las dimensiones prácticas y teóricas del entendimiento (como en Kant), ni descubrir verdades allende a la propia razón práctica (como el intuicionismo moral), sino el entendimiento público entre ciudadanos que se conciben a sí mismos como libres e iguales.

Finalmente, la idea de objetividad normativa en el contexto de una teoría política constructivista, para la justificación pública de sus principios, allende el procedimiento de construcción, comprende la reunión copulativa de ciertas notas básicas. Entre ellas destacan la publicidad, en la esfera de lo político, de los juicios e inferencias realizadas a propósito de ellos; la existencia de un procedimiento idóneo para la resolución de la controversia política; el establecimiento exhaustivo, dentro del procedimiento precedente, de los criterios de valoración de los argumentos y ponderación de las razones afirmadas por los ciudadanos o sus representantes; la posibilidad de explicar en forma satisfactoria los desacuerdos en la esfera de lo político. La idea de objetividad, en este sentido, se entiende es una posibilidad de la razón práctica que, a su vez, supone que los ciudadanos son razonables.

En suma, que la justicia como equidad sea una teoría política constructivista quiere decir que tiene como objeto la determinación de principios de justicia destinados a regular la estructura básica social y que esos principios, por su parte, son expresión de valores propiamente políticos de un régimen democrático constitucional y, por lo mismo, son congeniales con las ideas de ciudadanos libres e iguales y de sociedad entendida como esquema de cooperación equitativa que demanda para su funcionamiento un entendimiento público y satisfactorio de sus integrantes.

respeto hacia las personas que descansa ya en una doctrina del derecho natural (Dworkin, 1977) ya en la doctrina ética kantiana (Larmomre, 1999) que nunca es totalmente explícita”, Audard, Catherine (2007) John Rawls. Trowbridge: Acumen Publishing, p. 284. 


\section{4) ALgunaS CONSIDERACIONES CRÍTICAS FINALES}

La estrategia metodológica adoptada por Rawls a partir de los años 80 para la justificación de su teoría de la justicia puede ser evaluada desde una doble perspectiva. En primer lugar, está la cuestión de si el enfoque constructivista político que adopta Rawls como clave interpretativa de sus ideas es el único medio de afirmar principios sustantivos de justicia. En segundo lugar, podemos preguntarnos si el constructivismo político propuesto por Rawls tiene la aptitud de justificar los principios sustantivos de justicia que definen a la teoría de la justicia como equidad. Aunque se trata de preguntas conexas entre sí, la verdad es que avanzan en direcciones un tanto diversas.

La primera cuestión tiene que ver con la relación que toda teoría constructivista establece entre un enfoque ético y metaético. Desde esta posición la cuestión se traduce en si la estrategia constructivista aporta un contenido sustantivo diverso a las teorías éticas realistas, emotivistas y naturalistas. Esta primera interrogante se resuelve desde la propia óptica de justice as fairness entendida como una teoría meramente política. Según Rawls, los principios de justicia propuestos por la teoría pueden ser afirmados por un conjunto de teorías comprehensivas del bien, pues estos principios son congeniales con los principios sustantivos de todas las teorías éticas "razonables". Si esto es así, en consecuencia, la importancia de la estrategia seguida por Rawls (la adscripción de su teoría al constructivismo ético) no ha de buscarse tanto en el contenido sustantivo de su teoría como en la orientación metodológica de la misma, esto es, en su enfoque metaético.

Solo desde el horizonte de la metaética podemos intentar responder a nuestra segunda cuestión, a saber, en qué medida el constructivismo ético en general, y el constructivismo político de Rawls en particular, está en condiciones de justificar principios sustantivos de justicia. En otras palabras qué justifica la adopción de una teoría constructivista y de qué manera se justifica la elección de los elementos de construcción de la teoría.

Como hemos advertido en las páginas precedentes, lo que caracteriza en general al constructivismo ético es la adopción de un punto de vista establecido por la razón práctica, que tiene por objeto responder a una cuestión ética mediante el establecimiento de un procedimiento de discusión intersubjetiva en condiciones selectas, que tiene la aptitud de generar una respuesta correcta al problema planteado, determinando tanto los principios rectores de solución del problema como los criterios decisorios de aplicación de los principios éticos sustantivos (cuestiones de jerarquía, prelación, competencia, etc.).

Rawls mismo advierte que existen muchos tipos de constructivismo ético y que el suyo propio es un tipo de constructivismo político que 
toma distancia del constructivismo kantiano. No entraremos aquí en la cuestión de determinar qué tipo de teorías pueden ser consideradas variantes del constructivismo ético. Nos interesa, en cambio, reparar brevemente y en términos generales en el constructivismo kantiano y considerar en qué medida está en condiciones de justificar principios de justicia. La cuestión tiene interés toda vez que Rawls, en un primer momento, había anclado su teoría constructivista en el horizonte de la filosofía kantiana y, en tal sentido, las bases de apoyo que aquella proporcionaba permitían resolver la cuestión de la justificación del método mismo. Sin embargo, al desmarcar a justice as fairness del ideario kantiano, Rawls debe buscar nuevos puntos de apoyo para la justificación del constructivismo político. En este punto, como veremos, ya no resulta tan claro que el constructivismo político esté en condiciones de justificarse a sí mismo de manera constructivista. Revisemos, pues, brevemente, de qué trata el constructivismo ético kantiano.

Kant piensa que, así como en el ámbito de la razón pura especulativa es posible encontrar un conjunto de categorías independientes de la experiencia que dan cuenta de la propia legalidad de la razón en la búsqueda de la verdad, en el dominio de la razón pura práctica ${ }^{45}$ es posible hallar principios independientes de la experiencia que expresan su propia legalidad en el ámbito del obrar ${ }^{46}$. Estos principios éticos determinan la voluntad de los individuos bajo la forma de "imperativos categóricos", esto es, máximas de conducta que representan principios de una legislación universal de sujetos moralmente autónomos y que se resumen en la famosa formulación kantiana de "obra de modo tal, que la máxima de tu

45 La división de la razón en teórica y práctica no fue una invención kantiana, sino aristotélica. Aristóteles, en efecto, había distinguido un uso práctico y uno teórico de la razón, siendo el primero un subordinado del segundo y, por igual motivo, la ética una consecuencia necesaria de los principios ontológicos (del ser). De tal suerte que, para Aristóteles, el descubrimiento del ser condiciona al obrar. Kant, por el contrario, piensa que existe una subordinación de lo que fácticamente es a lo que debe ser, por lo cual es la razón teórica la que tiene que estar subordinada a la razón práctica, pues solo esta nos abre el camino de lo trascendente. Es fácil apreciar el abismo que separa a la filosofía clásica de la kantiana, no solo por la inversión que opera entre el "ser" y el "deber ser", adquiriendo este último más importancia que el primero, sino también por la nueva concepción de obligatoriedad que se introduce en la filosofía moral. Pues con Kant el pensamiento occidental va a transitar de una moral heterónoma informada por la prosecución de fines externos o, peor aún, por la evitación del castigo o la búsqueda de recompensa, a una autónoma informada por el principio de la independencia de la voluntad. Solo en la voluntad libre descansa la posibilidad de realización de un mandato conforme a los principios prácticos del obrar, esto es, la realización de un imperativo categórico.

46 Siendo tales principios "proposiciones que encierran una determinación universal de la voluntad, a cuya determinación se subordinan diversas reglas prácticas”. KANT, Immanuel (1990 a) Crítica de la Razón Práctica, México D.F.: Editorial Porrúa, p.103. 
voluntad pueda valer siempre, al mismo tiempo, como principio de una legislación universal" 47.

Ahora bien, los sujetos morales pueden subordinarse a las normas morales de diversa manera. En efecto, según Kant se pueden obedecer por mera conveniencia o porque efectivamente el sujeto moral adhiere en conciencia a ellas. En el primer caso estaremos frente a una conducta realizada conforme a la "legalidad" de la acción, mientras que en el segundo estaremos frente a una que se funda en la "moralidad" de la misma. Pues bien, la validez moral de una conducta depende de la moralidad de la acción, pues solo ella expresa el grado de autonomía moral que demanda un sujeto premunido de una buena voluntad ${ }^{48}$. En efecto, solo el recto cumplimiento de los imperativos categóricos manifiesta en su realización la autonomía del sujeto moral, esto es, la interna armonía de la voluntad consigo misma y su naturaleza trascendente, independiente de toda condición externa, sea esta temporal o espacial.

Mediante el cumplimiento (moral) de los imperativos categóricos, el individuo (noumenal y trascendental) se ubica por encima del ámbito existencial concreto del sujeto empírico ${ }^{49}$, y obrando de tal modo se reconoce a sí mismo como miembro digno de lo que Kant llama "el reino de los fines".

En consecuencia, y en términos muy generales, desde la perspectiva de Kant se obra éticamente cuando se actúa conforme a un imperativo categórico asumido como expresión de la propia voluntad individual. Puesto que los imperativos categóricos, a su vez, expresan una ley universal de acción, la adecuación de la conducta individual a los mismos no es otra cosa que manifestación de la autolegislación individual que se condice con la de todos los sujetos morales autónomos y que conforma, con prescindencia del sujeto y las condiciones empíricas, el llamado reino de los fines, constituido por el conjunto de principios morales que hacen posible la verdadera libertad de los individuos, es decir, aquella libertad que proviene de la autodeterminación individual y que es manifestación de la legislación universal de una buena voluntad.

$47 \quad$ Kant (1990 a) 112.

48 "Una voluntad perfectamente buena hallaríase, pues, igualmente bajo leyes objetivas (del bien); pero no podría representarse como constreńida por ellas a las acciones conforme a la ley, porque por sí misma, según su constitución subjetiva, podría ser determinada por la sola representación del bien. De aquí que para la voluntad divina y, en general, para una voluntad santa, no valgan los imperativos: el 'deber ser' no tiene aquí lugar adecuado”. KaNT, Immanuel (1990 b) Fundamentación de la Metafísica de las Costumbres. México D.F.: Ed. Porrúa, p. 35.

49 "Hay un imperativo que, sin poner como condición ningún propósito a obtener por medio de cierta conducta, manda esa conducta inmediatamente. Tal imperativo es categórico". Kant (1990 b) 36 . 
Desde la perspectiva kantiana, por tanto, la adopción de una teoría constructivista en ética se encuentra justificada por la propia consideración de los sujetos morales autónomos. Así se resuelve en la filosofía de Kant, por una parte, el problema del "punto de vista" práctico supuesto en las teorías constructivistas y, por otra, la legitimación de procedimientos "conjeturales" de elección de principios morales, políticos y jurídicos.

Rawls, en su primera aproximación al constructivismo ético como teoría metaética supuesta en justice as fairness, transita con una serie de matices propios un derrotero similar al de Kant. Adopta, al igual que el prusiano, el punto de vista práctico de los sujetos morales autónomos y deriva de este (mediante el recurso heurístico de la posición original) los principios de justicia (equivalentes a los imperativos categóricos) que han de ser el criterio a priori de evaluación de las principales instituciones sociales.

Pero en Political Liberalism, como hemos señalado, Rawls libera su teoría de la justicia de su dependencia respecto de la filosofía kantiana y, con ello, la idea de una razón práctica constitutiva de la moralidad en términos de autonomía de los sujetos morales, para situarse en el horizonte de una teoría constructivista que ahora se concibe a sí misma como teoría política en el sentido que ya conocemos. El desplazamiento se explica, en parte, porque con el paso del tiempo Rawls terminó pensando que la idea de autonomía moral al modo kantiano no tenía la aptitud suficiente para generar las bases de consenso social que demanda una teoría de la justicia llamada a ser implementada en el marco de un régimen democrático y constitucional caracterizado por la pluralidad de puntos de vista de los ciudadanos.

Sin embargo, es precisamente a propósito de esta opción que surge la pregunta sobre si el constructivismo político propuesto por Rawls tiene la aptitud para justificarse a sí mismo como método de justificación de los principios sustantivos de justicia.

Respecto a esta pregunta, creemos, acontece en el constructivismo político propuesto por Rawls algo realmente interesante desde la perspectiva metodológica de la teoría. En efecto, resulta que para la justificación de la posición original (que justifica de manera constructivista la elección de los principios de justicia), Rawls recurre a la idea de "equilibrio reflexivo". El recurso metodológico no deja de llamar la atención, pues mediante esta estrategia Rawls vuelve a aproximar de manera peligrosa su propia teoría a una suerte de intuicionismo inductivo del cual, al parecer, progresivamente había querido escapar. En tal sentido, pensamos, al prescindir de la noción de "razón pura práctica constitutiva" al modo kantiano, Rawls priva a justice as fairness de una justificación propiamente constructivista de la teoría, restringiendo el método constructivista únicamente a la justificación de los principios de justicia (los principios se justifican 
constructivistamente desde la posición original). Desde esta perspectiva la idea de una teoría constructivista metaética ha perdido prácticamente todo su interés, pues, en último término, la propia posición original y los principios obtenidos a partir de ella pueden parecer superfluos en la medida en que, desde una perspectiva coherentista, ya se corresponden punto por punto con los juicios considerados en equilibrio reflexivo por parte de los miembros de la comunidad política. En otras palabras, la propuesta de Rawls a partir de Political Liberalism parece avanzar más bien en la dirección de una teoría reconstructivista y no meramente constructivista.

Ahora bien, en qué medida la solución que propone Rawls puede hacer frente a la crítica precedente y solucionar de manera satisfactoria las exigencias de justificación de la teoría de la justicia como equidad, es una cuestión que requiere una investigación independiente a este pequeño trabajo.

\section{Bibliografía}

- Alexy, Robert (1989) Teoría de la Argumentación Jurídica. Madrid: Centro de Estudios Constitucionales.

- Audard, Catherine (2007) John Rawls. Trowbridge: Acumen Publishing.

- Bunley, Michael (2010) "The Structure of Justification in Political Constructivism" in Metaphilosophy, Vol. 41, No 5.

- Dworkin, R. (1989) Los Derechos en Serio. Barcelona: Editorial Ariel.

- Gómez, Carlos (2007) "El Ámbito de la Moralidad: Ética y Moral", en La Aventura de la Moralidad, C. Gómez y J. Muguerza (eds.). Madrid: Alianza Editorial.

- Graham, Paul (2009) Rawls. Glasgow: Oneword Publication.

- Habermas, Jürgen (1988) Teoría de la Acción Comunicativa, Tomos I y II. Madrid: Editorial Taurus.

- Kant, Immanuel (1990) Crítica de la Razón Práctica, México D.F.: Editorial Porrúa.

- Kant, Immanuel (1990) Fundamentación de la Metafísica de las Costumbres, México D.F.: Editorial Porrúa.

- Korsgaard, Christine M. (2003) "Realism and Constructivism in Twentieth-Century Moral Philosophy", in Philosophy in America at the Turn of the Century APA, Centennial Supplement to Journal of Philosophy Researcha, Charlottesville, V.A.: Philosophy Documentation Center.

- Lorenzen, Paul (1969) Normative Logic and Ethics. Mannheim: Bibliographisches Institute A.G. 
- Levine, Andrew (2003) "Rawls's Kantianism", en John Rawls, Critical Assesments of Leading Political Philosophers, Volume I, Edited by Chandran Kukathas. London: Routledge.

- Massini Correas, Carlos (2004) Constructivismo Ético y Justicia Procedimental en John Rawls. México D.F.: Universidad Nacional Autónoma de México.

- Maturana, Humberto (1997) La Objetividad, Un Argumento para Obligar. Santiago: Editorial Universitaria.

- Nino, Carlos (1989) El Constructivismo Ético. Madrid: Centro de Estudios Constitucionales.

- O’Neill, Onora (2003) "Constructivism vs. Contractualism”, in Ratio (new series) XVI, 4.

- O'Neill, Onora (2003) "Contructivism in Rawls and Kant", The Cambridge Companion to Rawls, Edited by S. Freeman. New York: Cambridge University Press.

- Rawls, John (1971) A Theory of Justice (original edition). Massachusetts: Harvard University Press.

- Rawls, John (1985) A Theory of Justice. Oxford: Oxford University Press.

- Rawls, John (2000) A Theory of Justice (Revised Edition). Massachusetts: Harvard University Press.

- Rawls, John (1999) "Kantian Constructivism in Moral Theory", Collected Papers, Edited by S. Freeman. Massachusetts: Harvard University Press.

- Rawls, John, (1999) "The Independence of Moral Theory", Collected Papers, Edited by S. Freeman. Massachusetts: Harvard University Press.

- Rawls, John (2005) Political Liberalism (Expanded Edition). New York: Columbia University Press.

- Rodilla, M.A. (2006) Leyendo a Rawls. Salamanca: Ediciones Universidad de Salamanca.

- Rubio Carracedo, José (1987) El Hombre y la Ética. Barcelona: Editorial Anthropos.

- Rubio Carracedo, José (1992) Ética Constructiva y Autonomía Personal. Madrid: Editorial Tecnos.

- Streb, James A. (2006) "Moral Realism and Kantian Constructivism", in Ratio Juris, Vol. 19, no 4.

- Street, Sharon (2010) "What is Constructivism in Ethics and Methaethics", in Philosophy Compass 5/5.

- Wallner, Fritz (1994) Ocho Lecciones de Realismo Constructivo, Valparaíso: Ediciones Universitarias de Valparaíso. 